\section{Clinical dectures}

\author{
DELIVERED AT
}

\section{CHARING CROSS HOSPITAL.}

BY

HYDE SALTER, M.D., F.R.S.,

FHLLOW OF THE ROYAL COLLEGE OF PHYSICIANS; LECTURER ON PHYSIOLOGY AND PATHOLOGY AT CHARING CROSS HOSPITAL MEDICAL SCHOOL; AND ASSISTANT. PHYSICIAN TO THE HOSPITAL.

Lecture II (concluded). - ON HaMaturia.

Prognostic Value of the Disappearance of the Blood. Diagnosis of Pure Hcematuria from Albuminuria plus Homaturia. Special Proclivity of Kidneys to Hamorrhage. Rationale of the Persistence of Hamaturia. Case of Blood-Cast of Ureter. Treatment.

CASE II. Elizabeth Neale, aged 57, a tall, pale woman, with a good deal of œdema about her face, by occupation a monthly nurse, and always temperate, was ad. mitted into the Bow Ward, Bed No. 5, March 13. She was well up to the 20th February, when she was seized with shivering and pain in the bowels and back, especially in the region of the left kidney, from having slept in a damp bed. This was soon followed by swelling of the face, fever, and constant vomiting; and this by the appearance of blood in the urine. The urine rapidly became darker, and in a day or two was almost black. The vomiting was constant; she hardly passed balf an hour without suffering from it; and the symptoms of bronchitis -cough, dyspnoea, and expectoration-supervened. She went on in this state for a fortnight (three weeks from her first symptoms), when she was admitted as an in-patient. Two davs before she was admitted she was seized with diarrhoa, which continued a week after her admission. In the week intervening between the shivering at the commencement of her illness and the appearance of the blood, the urine was scanty, -not more than half a pint in twenty-four hours, and that sometimes passed only once; when, however, the hæmorrbage appeared the quantity of urine became more abundant and continued so up to her admission, at which time she was passing three or four pints.

When admitted into the hospital her symptoms were of two kinds, bronchitic and renal; and the former were so urgent that for the first day the latter were over looked. She could only breathe bolstered up in bed; the cough was constant; the expectoration abundaut; and crepitant and sonorous rhonchi were heard all over the chest. The next day the nurse called attention to the urine, and it was found to be in the state described-absolutely black with blood. Associated with this was a constant pain, day and night, in the ragion of the left kidney, aggravated by movement, and rising, sometimes once a day, sometimes more frequently, into paroxysms of great severity. Deep pressure in the seat of the pain, and beneath the left false ribs, was intolerable. The face was as much puffed 28 it had been at all; the tongue was clean; the pulse feeble.

When first attention was directed to the source of the hæmorrhage, the idea was entertained that it might possibly depend on calculus in tbe kidney; and this idea was suggested by the paroxysmal character of the pain, by its restriction to one side, by its aggravation on movement, and by the vomiting. On examination by the microscope, although the quantity of blood was so large, no blood-casts could be found; the search was repeated day by day with similar ill success. Casts were then found in abundance, and continued to be so, until the quantity of blood became so small that the fibrine was insuffi. cient to form firm coagula. (Query. Was the failure to detect blood-casts in the first place, due to the flow of blood being so profuse that it had not time to coagulate in the tubes, or to want of care in the examination? The constancy with which they were afterwards discovered would imply the former explanation if it is a possible one.)

It was ten days or a fortnight befora the bronchitic symptoms gave way. The pains in the loins, and the almost constant ve miting were relieved by hydrocyanic acid and opium in an effervescing vehicle, and counterirritants to the seat of pain.

For two months, that is up to May 21st, various forms of astringents and iron were administered, in the hope of diminishing the hæmorrhage; but I cannot say with any decided benefit. At one time I gave :-

B Tincturæ ferri sesquichlor. $m x$; acid. nitro-hydrochlor. dil. 3 ss ; tiucturæ opii $m x$; infusi calumb. そiss. M. Fiat haustus, ter in die sumendus.

At another time :-

B Acidi gallici gr. $\mathrm{x}$; tincturæ opii $\mathrm{m}_{\mathrm{x}} \mathrm{x}$; acidi nitrici dil. MXx ; decocti cinchon. $\bar{z}$ iss. M. Fiat haustus, ter in die sumendus.

At another time she had :-

R Quinæ disulph. gr. i; acidi sulph. dil. $m \times x$; ferri sulph.gr. iij; infusi calumb. そiss. M. Fiat haustus, ter in die sumendus.

On May 21st, I ordered dry cupping to the loins, and an immediate and marked improvement took place, I must say, contrary to my expectation. The blood in the urine was conspicuously less, the pain nearly gone, and the patient felt in every way better. Was this a coincidence or a consequence? I must confess myself to be rather a sceptic with regard to dry cupping. The only way in which it could act in such a case as this would be as a counterirritant; and why it should act so differently from other counterirritants, I am at a loss to explain. However, its daily application was attended with a daily improvement in the condition of the urine, the smoky colour of which became paler and paler; and on the 3uth, it was pronounced not smoky and free from albumen. - 'he quantity of blood never rose again to what it had been before the dry cupping, although on two occasions, June 1 st and June 11 th, it returnel in consider. able quantity, in consequence, both times, of exposure to cold. The following is a table of the principal characteristics of the urine since the 22nd of May, when it began to amend.

\begin{tabular}{|c|c|c|c|c|c|}
\hline Date. & $\begin{array}{l}\text { Quan- } \\
\text { tity. }\end{array}$ & Sp.gr. & $\begin{array}{l}\text { Reac. } \\
\text { tion. }\end{array}$ & Albumen. & Observations. \\
\hline Iay 22 & $2 \mathrm{pts}$. & 1016 & Acid. & Abuudant. & Very smoky. \\
\hline „23 & Do. & 1020 & Do. & Less & Smok \\
\hline , 24 & Do. & 1014 & Do. & Very little. & 1.ess smoky. \\
\hline$" 25$ & Do. & 1016 & Do. & A trace. & $\begin{array}{l}\text { Scarcely at all } \\
\text { sinoky. }\end{array}$ \\
\hline 26 & Do. & 1014 & Do. & Do. & Do. \\
\hline$\# 28$ & 1)o. & 11115 & Do. & Do. & Bo. \\
\hline$" 29$ & $2 \$ \mathrm{pts}$. & 1010 & Do. & $\begin{array}{l}\text { Slightest } \\
\text { trace. }\end{array}$ & Do. \\
\hline " 30 & 2 pts. & 1014 & Moreso. & None. & Not smoky. \\
\hline & Do. & 1015 & Do. & Do. & Do. \\
\hline June 1 & $2 \$$ pts. & 1012 & Acid. & More. & M.re smoky. \\
\hline " 2 & Do. & 1014 & Do. & Less. & J.ess smoky. \\
\hline $\begin{array}{ll}\Rightarrow & 4 \\
& \end{array}$ & $\begin{array}{l}2 \frac{1}{2} \text { pts. } \\
\text { Do. }\end{array}$ & $\begin{array}{l}1016 \\
1015\end{array}$ & $\begin{array}{l}\text { Do. } \\
\text { Do. }\end{array}$ & $\begin{array}{l}\text { Decreasing. } \\
\text { slightest } \\
\text { trace. }\end{array}$ & $\begin{array}{l}\text { Do. } \\
\text { Not smoky. }\end{array}$ \\
\hline 6 & Do. & 1015 & Do. & Do. & Do. \\
\hline$"$ & Do & 1015 & Do & None. & 1) \\
\hline & $3 \frac{1}{2}$ pts. & 1016 & Do. & 'Truce of. & Rnther smoky. \\
\hline$" 9$ & Io. & 1012 & Do. & I.ess. & Less smoky. \\
\hline$" 11$ & $2 \frac{1}{2} p t s$ & 1019 & Do. & $\begin{array}{l}\text { Much in- } \\
\text { creased. }\end{array}$ & $\begin{array}{l}\text { Very smoky in. } \\
\text { deetl. }\end{array}$ \\
\hline$" 12$ & $2 \frac{1}{4}$ pts. & 1014 & Do. & l.ess. & l.ess smoky. \\
\hline " 15 & $\begin{array}{l}2 \frac{1}{2} \text { pts. } \\
\text { Do. }\end{array}$ & $\begin{array}{l}1015 \\
1017\end{array}$ & $\begin{array}{l}\text { 110. } \\
\text { ho. }\end{array}$ & $\begin{array}{l}\text { Still less. } \\
\text { l.ess. }\end{array}$ & $\begin{array}{l}\text { Much less su } \\
\text { Less sinoky. }\end{array}$ \\
\hline 16 & Do. & 1017 & Do, & Do. & Do. \\
\hline " 18 & Do. & 1017 & Do. & Hardly any. & $\begin{array}{c}\text { Senrcely nt all } \\
\text { smoky. }\end{array}$ \\
\hline
\end{tabular}


But we must guard dgainst the error of imagining that because the blood is disappearing the patient is necessarily recovering. In these cases it was so ; but it is possible for the blood to disappear entirely, and yet for the kidney to be "going to the bad"; while the hæmorrhage is ceasing the gland may be undergoing a gradual process of disorganisation. The blood may disappear, but the urine may still be albuminous; or it may never recover its proper quantity; or the amount of solids seereted, as indicated by its specific gravity, may fall more and more below the normal standard; or a sediment, consisting of the morphological elements of the kidney, may be always present in greater or less quantity. Only when the disappearance of the blood is accompanied with other favourable changes in the urine, can we regard it as an important and positive prognostic sign. If with the blood the albumen also vanishes; if the urine recovers its natural quantity and specific gravity; and all organised deposit absolutely ceases ; in a word, if the secretion recovers, in every respect, its normal character, then, and only then, do we know that all is going on well with the kidney. The disappearance of the albumen with, and in proportion to, the disappearance of the blood (so well shown in the above table), is, I think, a most important and satisfactory sign.

And here let me remind you, that an urine containing blood, and yielding, on the application of its tests, a deposit of albumen, may be symptomatic, either of hæmaturia only, or of hæmaturia plus albuminuria; and whether it shews the first only of these conditions, or both of them, will depend upon the quantity of the albumen in relation to the quantity of the blood, as shown by the colour of the urine, etc. If, with a considerable amount of smokiness, we have but a scanty deposit of albumen, then the condition is that of hæmaturia alone, the albumen entirely that of the blood; if, on the other hand, there is an abundant albuminous deposit, with but slight smokiness, then it is a case of albuminuria as well as hæmaturia ; for the amount of albumen is greater than the blood will cover, or account for. In cases of simple hæmaturia, it is surprising how small an amount of albumen will be thrown down, even when the presence of blood, as shown by colour, is not only recognisable, but conspicuous. I have frequently been surprised, in examining the urine of the woman Neale, to see how little albumen it contained, even when it was quite smoky; and on one or two occasions in which I should not have hesitated to detect the presence of blood by the eye, heat and acid have only given the slightest opalescence; the clearness of the urine has hardly been disturbed. It is in these cases, where the albuminous deposit is so small, that we find it diminishing pari passu with the smokiness and the microscopical evidence of the existence of blood, and ultimately vanishing altogether with them. In fact, we have here no serous transudation at all; but merely some of the Malpighian capillaries which have been ruptured, still permitting the escape of the blood-elements.

It is impossible to have the attention much directed to renal disease without being struck with the facility with which the kidney becomes the seat of hæmorrhage. Every time an asthmatic suffers from a paroxysm of his disease, his pulmonary cir- culation is thrown into the same state as that of the kidney in hæmaturia from chill; and yet how rarely does bæmorrhage from the lungs occur in asthma. Nay more, in the prolonged asphyxia of fatal croup or laryngitis, where the blood in the engorged capillaries is gradually being brought to a standstill, the tension of the capillaries is rarely relieved by hæmorrhage. I know of no system of vessels in the whole body, except perhaps those of the Dehneiderian membrane (and I am not sure even of them), that so readily become the seat of hæmorrhage as the Malpighian capillaries ; they often appear to yield to the slightest disturbance of the balance of the renal eirculation. And I think we may find the explanation of this in that special anatomical arrangement to which Mr. Bowman has called attention, which enables them, in health, to appreciate the slightest variations in the conditions of osmotic balance, keeping the blood within them in a state of more or less tension, and thus favouring the transudation of its watery portions. Mr. Bow man points out that the collective volume of the Malpighian capillaries being much greater than that of the Malpighian artery tributary to them, the blood experiences in them a retardation of its course, a circumstance in itself favouring transudation; and further, that the blood of the capillaries being collected into a single vein, the Malpighian, whose volume is, like that of the artery, much less than the aggregate volume of the capillaries, an impediment to its free exit from the capillaries is established, and its state of tension in these vessels increased, just as narrowing the outlet of a reservoir increases the pressure of its contents against its sides. This arrangement, within the confines of health, produces only the free escape of the water of the blood, and renders the Malpighian-tufts delicate filters, taking cognisance of the slightest variations in the conditions affecting osmosis, such as the volume of the blood, its watery condition, or the reverse. But if the tension in the Malpighian capillaries is increased by the establishment of some additional obstruction in front of them, as in the intertubular capillaries, not only the water of the blood, but its serum, will escape; if it is still further increased, not only will serum escape, but liquon sanguinis; and if still further, the capillaries will give way, and blood will be effused.

Another fact, hanging upon this facility of rupture to which I have just referred, and which these two cases well illustrate, is the obstinacy with which hæmorrhage from the kidneys, when once established, persists. The very circumstance that disposes the Malpighian capillaries to yield, and favours the escape of blood from them, tends to keep up the bleeding when once they have ruptured, and make it difficult of arrest. And even when the discharge of blood has almost ceased, and we are congratulating ourselves on being "out of the wood" at last, the slightest thing will bring it back again-much less than in the first place would have induced it. When once the balance of the renal circulation has been thrown out, it takes a long time to re-settle, and manifests its perturbations, whether by the escape of blood or of albumen, with a most inconvenient facility.

In the case of the boy Corke, the bleeding has existed for ten weeks, and in the case of the woman. Neale for upwards of three months; and even now,: 
though there is but a trace left in either, it cannot be said completely to have ceased; yet the condition of the urine, and of the patient in other respects, warrants a favourable prognosis, although it is impossible to say when the blood will entirely and finally disappear.

Both these cases illustrate the importance of the microscopical examination of the urine. In both of them the diagnosis of the nature and seat of the hæmorrhage was rendered certain, and alteruative rendered impossible, by finding blood-casts.

And here let me relate to you a case of hrmaturia which lately came under my observation, in which the seat of the hæmorrhage was diagnosed by finding a blood-cast of a much larger tube than the microscopical ones of the kidney, namely, the ureter. The patient was a hale looking man, in the middle of life, who had suffered from passing blood in his water at intervals for nine years past. For months he would lose so much blood that it seemed as if he would bleed to death, and then for months, or even for a year or two, his symptoms would entirely cease. When I saw him he had the look of a florid man blanched; there was colour in his cheeks, but the rest of his face, his lips, and conjunctivæ, were white. He was passing so much blood in his urine, that at times a firm coagulum was formed in the $p \delta t$ de chambre. He had been a railway porter, and attributed the first access of his symptoms to overlifting himself. The curious part of his case was that, except the passage of the blood, he suffered from no symptom whatever; no functions were disturbed; there was no pain; and nothing to localise the hæmorrhage. The case looked, perhaps, more like calculus in the kidney than anything else, except for the absence of the characteristic symptoms of that condition; there was, as I have said, no pain; there was no retraction of the testicle; no vomiting. There were, also, no bladder symptoms. Under these circumstances, it seemed impossible to say where the blood came from. A few days after I had seen him, my friend Dr. Wickham Barnes of Islington, under whose care he was, sent me something looking just like a worm, which had been passed from the bladder in making water. It was six inches long, cylindrical, pointed at each extremity, and coiled up. The patient's son declared that he had seen it move just after it was voided; and it was sent to me as a veritable worm. On examining it, I found it to be a coagulum of fibrine, and saw at once, from its shape, that the only place in which such a mould could have been formed was the ureter. It, therefore, clearly showed that the blood came from above the ureter, that is, from the kidney. And, thus, the problem of the seat of the hæmorrhage was solved by this single circumstance.

And now a word or two about treatment.

In the form of hæmaturia that the cases of Corke and Neale exhibit, which we may call Malpighian hæmaturia, there are four indications to be compassed by treatment.

1. Preventing a recurrence of the exciting cause by guarding the skin from chill.

2. Checking the hæmorrhage by astringents.

3. Supplying that of which hæmorrhage tends directly to rob the blood, and which more than anything expedites sanguification, namely iron.

4. Meeting symptoms as they arise, such as pain, romiting, etc.
The first condition I secure by keeping the patient in bed, generally between blankets; this has the advantage of additional warmth, a certain amount even of cutaneous rubefaction, and prevents any chill from wet sheets in case the patient sweats; it allows also, in consequence of the increased warmth, of having a less incumbent weight of bedclothes, and so permits a freer ventilation from the patient's body. I think the perfection of covering for such patients is nothing but blankets, neither sheets nor counterpanes; blankets are at once warmer and more porous. I do not think, in relation to the skin, that anything is gained by sweating; I do not think we have any clinical evidence for believing that the skin is doing its other work better because it is throwing off a large quantity of water in addition; and it certainly tends greatly to exalt the sensitiveness of the skin, and to increase the chances of chill.

Of antihæmorrhagics, I think gallic acid and other vegetable astringents, and the mineral acids, are the best that we can give; I think, too, that opium has a marked antihæmorrhagic effect. There is one drug of which, as a general antihæmorrhagic, I think more highly than any other, viz., turpentine; this, however, we dare not give in such cases as these; indeed, we know that it will bring on the very condition of which I am speaking. I remember once seeing in one of the hospitals of this metropolis, a case of hæmaturia after scarlatina, in a girl about 15 years of age, for whom turpentine was prescribed; its administration was followed by so profuse an increase of the hæmorrhage, that in forty -eight hours the child sank under it. Even the external application of turpentine is not safe, nor even cantharides; if, therefore, I wish to apply counterirritants to the loins, I never blister nor apply turpentine stupes; but content myself with mustard plasters, or some other form of counterirritation. This is not a pedantic or imaginative caution.

Iron is in every way of great value ; as a general tonic, as supplying an essential ingredient of that portion of the blood, hæmatine, which is the slowest of repair; and in some of its forms, as the sulphate and tincture of the sesquichloride, as an astringent.

When the pain in the loins is severe, opium internally, and counterirritation locally, give most relief. If it is attended with vomiting, some benefit may be derived from the ordinary remedies for sickness, such as creasote and morphia, or hydrocyanic acid; but, as far as I have seen, not much. The vomiting, being sympathetic with the kidney, and not primarily gastric, does not yield to direct stomach treatment; what best relieves the condition of the kidneys and the pain in the loins best relieves the vomiting. The bowels should be kept freely open, inasmuch as loaded bowels mechanically incommode and irritate the kidney, and inasmuch, too, as the œdema may be diminished and the kidneys helped by a little gentle watery purging.

With regard to food, I do not think spare diet does for these cases; they should be well fed. I think there is some reason in the idea of not giving an embarrassed kidney any unnecessary work in the elimination of superfluous nitrogenous matter; but I am quite sure that, at any rate when the acute stage is over, and the kidneys are doing their work 
well, the hæmorrhage will cease sooner under a highly nutritious diet than under a poor one. We know that hæmorrhage may be produced by defective nourishment alone, and that for some of its forms, as purpura and scurvy, feeding is the treatment. The more vigorous is nutrition, the more rapid is the repair of the capillaries already ruptured ; and the higher the standard of tissue-formation, the less likely will the capillaries be to give way, and the less chance will there be of hæmorrhage, either local or general.

\section{嗮hrstrations}

or

\section{HOSPITAL PRACTICE: METROPOLITAN AMD PROUINOTAL.}

\author{
ST. GEORGE'S HOSPITAL. \\ CASE OF DISLOCATION AND FRACTURE OF THE \\ ASTRAGAIUS. \\ Under the care of Prescott Hewett, Esq.
}

[Reported by Thomas P. Pick, Esq., Medical Registrar.]

RICHARD T., aged 35, was admitted into Fitzwilliam Ward, St. George's Hospital, on Feb. 26th, under the care of $\mathrm{Mr}$. Hewett. He stated that he was an omnibus conductor, and that half an hour before admission, while jumping from one "monkey-board" to the other at the back of the omnibus, he slipped and fell to the ground, falling with his right foot under him. In endeavouring to spring up, he again slipped, and the wheel of an omnibus coming in the other direction passed over his foot. He was drunk at the time. He formerly drank considerably, but latterly not so much.

When he was admitted, there was found to be such injury to the foot as precluded the hope of saving the limb. Mr. Hewett, therefore, performed amputation at the lower third of the leg under chloroform, by making a circular incision through the skin and flap through the muscles. There was considerable bruising of the skin where the incisions were made, and the leg was taken off thus low down at the man's own request. There was very little arterial bleeding, four ligatures only being required; there was, however, slight oozing after the operation, for which ice was applied, which completely controlled it. Metallic sutures were used, and water dressing was applied.

Upon examining the limb after the operation, there was found to be an oval wound, four inches in length, on the outer side of the dorsum of the foot and ankle-joint, extending backwards as far as the tendo Achillis, and laying open the joint, which was dislocated; the tibia and fibula being thrown outwards and a little forwards. On passing the finger into the wound, a large cavity could be felt posteriorly; anteriorly, a peculiar prominence of bone. This was caused by a fracture of the astragalus, separating the superior third, which lies between the malleoli, from the rest of the bone. This articular surface was dislocated from the anklejoint and twisted upon jtself, projecting backwards and a little inwards, being attached to the internal malleolus by a few bands of ligamentous tissue. The external lateral ligament was torn through; the internal lateral or deltoid ligament was detached from the bone, but remained adherent to the periosteum, which latter was stripped off the tibia for some distance, carrying with it a small piece of that bone which was chipped off the malleolus.

There was a dislocation of the head of the astragalus from the scaphoid; the former bone being tilted up, 328 with its head directed downwards, and the surface articulating, with the os calcis looking directly backwards. A small portion of the os calcis, corresponding to the origin of the extensor brevis digitorum, was detached and carried upwards with the astragalus.

There was a small piece of bone lying loose in the wound; and some pieces of cartilage which had been torn from the calcaneo-astragaloid articulation. There was considerable bruising of the soft parts; but no vessel of any size was wounded.

Feb. 27th. $\mathrm{He}$ is reported to have passed a very. restless night; and appears to be this morning in a state of incipient delirium tremens. $\mathrm{He}$ is somewhat incoherent in his talk; his tongue is tremulous and furred; and his hand is shaky. Pulse 113; skin hot and dry. He says he is in no pain. He was ordered to take fifteen minims of tincture of opium in an ounce of camphor mixture three times a day; and to have ordinary diet and two pints of porter daily.

Feb. 28th. He has had some hours sleep during the night, and appears less restless this morning. Tongue still furred and tremulous. Pulse 92. There is an erythematous blush, and considerable tension of the stump, especially over the ends of the bone.

March 1st. The tension of the stump is less; the redness is fading. One or two small blebs have formed on the legs, and contain a sero-purulent fluid. He seems much quieter; tongue not so tremulous; hand steady; pulse 98.

March 2nd. The stump does not look so well. On the anterior flap, there is a dark red patch, which has every appearance of sloughing. Up the inner side of the calf, there is a red mark in the line of the absorbents; pulse 102, weaker; tongue clean, steady. Three of the sutures were removed, when a little pus exuded from the stump. He was ordered green digestive ointment, and a poultice to the stump; and to take five grains of sesquicarbonate of ammonia with ten minims of tincture of opium in an ounce and a half of cinchona draught three times a day.

March 4th. A slough has formed on the inner side of the anterior flap, where the bruising was most from the injury. There is less inflammation of the absorbents, and less tension of the stump; there is considerable redness of the flap over the end of the bone. All symptoms of delirium tremens have disappeared. All the sutures but one were removed.

From this date the patient went on well. A small slough separated on the $7 \mathrm{th}$, and free granulation took place, requiring the local application of a solution of nitrate of silver. All the ligatures came away ; and at present he is convalescent, and will probably leave the hospital in a few days.

Remarks. The mechanism of the foot is so perfect, the bones being wedged into each other so tightly, and bound together so firmly by strong ligaments, that dislocation of the bones of the tarsus is an exceedingly rare form of injury; but of these dislocations, luxation of the astragalus is, perhaps, the most frequent.

In the museum attached to St. George's Hospital, are two preparations which exemplify well the most common form of this injury; viz., dislocation of the head of the astragalus upwards on to the dorsum of the foot. One of these cases was, properly speaking, dislocation of the astragalus, together with the tibia and fibula, all of which were carried forwards. The other was dislocation of the os calcis and scaphoid from the astragalus.

The first of these cases was that of a middle-aged man, of corpulent habit, who met with the accident in getting out of a gig. Repeated attempts to reduce the dislocation were made without avail; and as considerable sloughing of the integuments took place, secondary amputation was performed. The following was the condition of the parts. The external malleolus was partially broken, the deltoid ligament still maintaining the con- 